\title{
Assignment of hitherto unidentified 165 rDNA species to a main line of descent within the domain Bacteria
}

\author{
Naomi Ward-Rainey, ${ }^{1}$ Fred A. Rainey, ${ }^{1}$ Heinz Schlesner ${ }^{2}$ \\ and Erko Stackebrandt ${ }^{1}$
}

\author{
Author for correspondence: Naomi Ward-Rainey. Tel: +495312616 101. Fax: +495312616418. \\ e-mail: rainey@gbf-braunschweig.de
}

1 DSM - Deutsche Sammlung von Mikroorganismen und Zellkulturen $\mathrm{GmbH}$ Mascheroder Weg $1 b$, Braunschweig D-38124, Germany

2 Institüt für Allgemeine Mikrobiologie, ChristianAlbrechts-Universitat, Kiel, Germany

\begin{abstract}
Phylogenetic analysis of the almost complete 165 rDNA sequence of the fimbriate prosthecate bacterium Verrucomicrobium spinosum confirms the unique phylogenetic position of this organism, as previously shown by oligonucleotide cataloguing and partial reverse transcriptase sequencing. Comparative 165 rDNA sequence analysis of $V$. spinosum with a group of environmental clones, considered to represent a novel phylum, reveals their relatedness, and allows assignment of these clones to a known main line of descent. This phylogenetic relationship is supported by the presence in the 165 rDNA sequence of $V$. spinosum of signature nucleotides previously considered unique for the environmental clone cluster.
\end{abstract}

Keywords: $16 \mathrm{~S}$ rDNA, Verrucomicrobium spinosum, environmental clone sequences

\section{INTRODUCTION}

The results obtained from molecular microbial ecology studies (mostly based on $16 \mathrm{~S}$ rRNA/rDNA analysis) have led to the suggestion that many more organisms exist in natural environments than have been isolated and characterized in pure culture. The molecular approach to microbial ecology has been applied to a wide range of environments. The first analyses of $16 \mathrm{~S}$ rRNA sequences obtained directly from environmental biomass were performed on cyanobacterial mats from Octopus Spring in Yellowstone National Park (Weller et al., 1991; Ward et al., 1990). This study demonstrated the failure of cultivation techniques to describe the full extent of biodiversity in a natural sample. The authors recovered sequences of cyanobacteria unrelated to Synechococcus lividans, the organism believed to be the sole cyanobacterial component of the mat, and other novel taxa, some of which could not be assigned to any known phylum. The first reports of 16S-rRNA-based molecular ecology studies of the marine environment described the composition of marine plankton from the Sargasso Sea (Britschgi \& Giovannoni, 1991; Giovannoni et al., 1990) and the Central Pacific (Schmidt et al., 1991). Both studies reported the recovery of $16 \mathrm{~S}$ rRNA gene sequences from members of the cyanobacteria and the Proteobacteria.

The EMBL accession number for the 16S rDNA sequence of $V$. spinosum is X90515.
While the cyanobacterial clones were closely related to cultured marine Synechococcus species (Giovannoni et al., 1990; Schmidt et al., 1991), 16S rRNA sequences were recovered that formed clusters within the alpha and gamma subdivisions of the Proteobacteria unrelated to cultured members of these subdivisions. The lack of close phylogenetic relationship between cloned environmental $16 \mathrm{~S} \mathrm{rRNA} / \mathrm{rDNA}$ sequences, and those available from previously sequenced pure cultures, recurred in subsequent investigations of marine environments (Fuhrman et al., 1993).

Novel archaeal groups have also been detected, including clones related to the methanogens in marine samples (De Long, 1992), numerous new lineages from thermal spring samples (Barns et al., 1994) and the Antarctic marine environment (De Long et al., 1994).

The 16S rRNA/rDNA techniques that were first applied successfully to aqueous samples have been subsequently employed in the investigation of other environments. The first molecular ecology study of the terrestrial environment was performed on a forest soil from Australia (Liesack \& Stackebrandt, 1992a, b; Stackebrandt et al., 1993). Among the findings of these investigations was the recovery of cloned sequences clustering within the radiation of the planctomycetes, and a novel clone group (Cluster III) sharing common ancestry with members of the planctomycetes and the chlamydiae. A third group were unexpectedly found to be deep-branching members 
of the order Actinomycetales, some of which were related to the iron-oxidizing strain TH3.

The most striking outcome of this study, as with the aquatic environments described above, was the recovery of sequences with only distant phylogenetic relationships to cultured micro-organisms. These findings have stimulated debate as to whether the cloned sequences represent so-called 'unculturable' or 'uncultured' organisms, or whether their apparent novelty is due to the fact that the $16 \mathrm{~S}$ rRNA/DNA sequences of many cultivated organisms are not available for comparison (Fuhrman et al., 1994; Ward et al., 1995). Given that the diversity of uncultured micro-organisms is considered to exceed that of cultured microbes by an order of magnitude, it is unlikely that sequences of cultured but as yet unsequenced strains will match closely those of environmental clones.

Here we demonstrate the relationship of the Cluster III $16 \mathrm{~S}$ rDNA clones, previously thought to be members of a novel line of descent (Liesack \& Stackebrandt, 1992b), to Verrucomicrobium spinosum, an organism for which full sequence data was not previously available.

\section{METHODS}

Verrucomicrobium spinosum strain $145^{\mathrm{T}}$ (IFAM 1439, DSM 4136) was cultivated on agar-solidified medium M13 (Schlesner, 1986). The extraction of genomic DNA and the amplification of $16 \mathrm{~S}$ rDNA were performed as described previously (Rainey $e t$ al., 1992). The PCR product was purified using the Prep-A-Gene kit (Bio-Rad) according to the manufacturer's instructions. The Taq DyeDeoxy Terminator Cycle Sequencing Kit (Applied Biosystems) was used to directly sequence the PCR product, following the protocol provided by the manufacturer. The sequence reactions were run on the Applied Biosystems 373A DNA sequencer.

The $16 \mathrm{~S}$ rDNA sequence of $V$. spinosum was aligned against a set of sequences of representatives of the main lines of descent within the domain Bacteria, and the clone sequences of Cluster III (Liesack \& Stackebrandt, 1992b). Pairwise evolutionary distances were computed using the correction of Jukes \& Cantor (1969). The least-squares distance method of De Soete (1983) was used in the construction of phylogenetic dendrograms from distance matrices. Phylogenetic analysis was also performed using the programs contained in the PHYLIP package (Felsenstein, 1993). Bootstrap values, which were based on the analysis of 1000 trees of 600 polymorphic sites, were calculated using the programs NJFIND and NJBOOT.

\section{RESULTS AND DISCUSSION}

The genus Verrucomicrobium, containing the species $V$. spinosum, was described for a group of strains isolated from the Vollstedter See, a small eutrophic lake in Holstein, Germany (Schlesner, 1987). The strains are prosthecate, but differ from other prosthecate organisms in being fimbriate (the fimbrae originating from the tips of the prosthecae), and in DNA base composition.

The almost complete $16 \mathrm{~S}$ rDNA sequence (1492 nucleotides) of $V$. spinosum was determined in this study. In a previous phylogenetic study (Albrecht et al., 1987), analysis was based on the $16 \mathrm{~S}$ rRNA catalogue, and 515

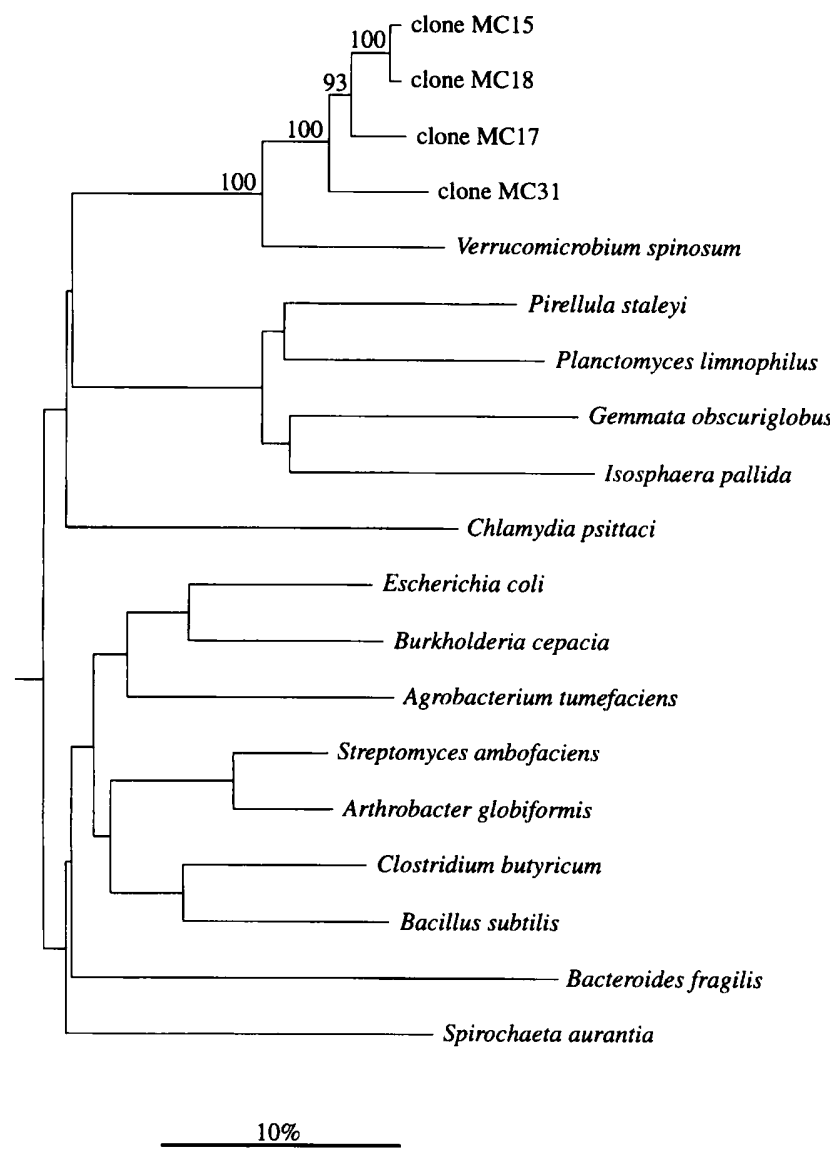

Fig. 1. Phylogenetic dendrogram indicating the position of Verrucomicrobium spinosum as a distinct lineage within the domain Bacteria, and demonstrating its relatedness to environmental clone sequences. The root was determined by the inclusion of the sequence of Thermotoga maritima. The scale bar represents 10 inferred nucleotide substitutions per 100 nucleotides.

nucleotides obtained by $16 \mathrm{~S}$ rRNA reverse transcriptase sequencing. The authors reported difficulties in determining sequence of the $5^{\prime}$ and $3^{\prime}$ regions of the molecule, due to sequence ambiguities at many positions, arising from fragmented rRNA or highly stabilized rRNA secondary structure. We did not encounter sequence ambiguities, probably because the direct sequencing of the PCR-amplified 16S rRNA gene circumvents the problem of secondary structure. The availability of the almost complete sequence allowed a more accurate determination of the phylogenetic position of $V$. spinosum. The phylogenetic position of $V$. spinosum as a distinct lineage within the domain Bacteria is shown in Fig. 1. The $V$. spinosum lineage would seem to share a common branching position with the planctomycetes and chlamydia lines of descent, but bootstrap values determined for these branching points were found to be insignificant.

Comparison of the $V$. spinosum $16 \mathrm{~S}$ rDNA sequence with all available $16 \mathrm{~S}$ rDNA sequences revealed a relationship to the Cluster III 16S rDNA clone sequences previously recovered from DNA that was isolated from an Australian 
Table 1. 16S rDNA similarity values between Cluster III clones, Verrucomicrobium spinosum, and Pirellula staleyi

\begin{tabular}{|c|c|c|c|c|c|c|}
\hline & Strain & 1. & 2. & 3. & 4. & 5. 6 \\
\hline 1. & Clone MC15 & - & & & & \\
\hline 2. & Clone MC18 & $98 \cdot 2$ & - & & & \\
\hline 3. & Clone MC17 & $95 \cdot 2$ & 93.9 & - & & \\
\hline 4. & Clone MC31 & $91 \cdot 8$ & $91 \cdot 3$ & $91 \cdot 4$ & - & \\
\hline 5. & Verrucomicrobium spinosum & $86 \cdot 2$ & $86 \cdot 5$ & $86 \cdot 1$ & 86.5 & - \\
\hline 6. & Pirellula staleyi & $73 \cdot 0$ & $73 \cdot 2$ & $73 \cdot 7$ & $72 \cdot 7$ & $72 \cdot 0$ \\
\hline
\end{tabular}

terrestrial soil. The $16 \mathrm{~S}$ rDNA sequences of the Cluster III clones were more highly related to $V$. spinosum than to any members of other lineages within the domain Bacteria.

$16 \mathrm{~S}$ rDNA sequence similarity values between the clones of Cluster III and $V$. spinosum ranged from 86.1 to $86.5 \%$ (Table 1). In the analysis described here, the Cluster III clones were shown to have similarities of $91 \cdot 3-98.2 \%$ to each other, in a similar range (89.8-97.5\%) to that found by Liesack \& Stackebrandt (1992b). Previous phylogenetic analysis based on a very small data set found $V$. spinosum to have highest sequence similarity to Escherichia coli (77.1\%) (Albrecht et al., 1987).

The phylogenetic relationship between $V$. spinosum and the Cluster III clones is clearly demonstrated by the topology displayed in the phylogenetic dendrogram (Fig. 1 ). The distant relationship of the Cluster III clones to, and possible common ancestry with, the planctomycetes and chlamydiae reported by Liesack \& Stackebrandt (1992b) is confirmed, as is the relationship of $V$. spinosum to these phyla (Albrecht et al., 1987). The phylogenetic depth of the $V$. spinosum group could be interpreted in two ways. Firstly, the taxa represented by the clone sequences, showing $86 \cdot 1-86 \cdot 5 \%$ similarity to $V$. spinosum, could be considered as species of the genus Verrucomicrobium; such low similarity ranges between species have been reported for other genera, for example the genus Spirochaeta (83-90\%)(Rainey et al., 1992). Alternatively, the clone sequences could represent species of a separate genus, since numerous examples exist in the literature of individual genera showing greater than $87 \%$ sequence similarity. Bootstrap analysis indicated that the $V$. spinosum/Cluster III clones group was recovered in all 1000 trees generated, thus demonstrating the phylogenetic coherence of this group. Phylogenetic analysis using other methods, e.g. neighbour joining, maximium likelihood and maximum parsimony, clearly showed the phylogenetic relatedness of the Cluster III clones to $V$. spinosum.

The 16S rDNA sequence of $V$. spinosum was examined for the presence of the signature nucleotides reported to be present in the sequences of the Cluster III clones by Liesack \& Stackebrandt (1992b). All of the signatures for the Cluster III 16S rDNA clones were found in the sequence of $V$. spinosum, as were those positions shared by the Cluster III clones and Cblamydia psittaci. These signature nucleotides support the phylogenetic relation- ship of Cluster III and $V$. spinosum, and the possible common ancestry of the Cluster III clones- $V$. spinosum lineage and the chlamydiae. The only exceptions were at positions 88 and 955 (E. coli numbering, Brosius et al., 1978), due to errors in the original report (Liesack \& Stackebrandt, 1992b). The nucleotide at position 570 pairs with that at position 880 , not 88 . At position 955 , the Cluster III clones and $C$. psittaci were reported to have a $\mathrm{U}$ residue. This residue is in fact a $C$ in $C$. psittaci, the Cluster III clones and $V$. spinosum, in common with the planctomycetes, and in contrast to other members of the domain Bacteria, which have a $U$ at position 955.

The discovery that cloned species from an acid soil are related to isolates from an alkaline lake $(\mathrm{pH} \mathrm{9.5)}$ is not necessarily surprising, as the study of Liesack \& Stackebrandt (1992b) also demonstrated the presence in soil of planctomycete sequences, while all pure cultures of planctomycete species and all as-yet uncultured planctomycete species have been isolated from, or observed in, only aquatic samples. Liesack \& Stackebrandt (1992b) pointed out that growth requirements within the planctomycetes vary widely, and that the four planctomycete genera have not been found together in the same habitat. Therefore, it is also possible that the phylogenetic group presently represented by $V$. spinosum and the Cluster III $16 \mathrm{~S}$ rDNA clone sequences contains taxa of widely differing physiological types living in diverse environments.

The results of this study demonstrate the potentially useful information that resides in already cultured organisms for which either no $16 \mathrm{~S} \mathrm{rRNA} / \mathrm{rDNA}$ sequence, or only partial sequence, has been determined. This information, if available, would be a valuable resource in comparative analysis of cloned environmental $16 \mathrm{~S}$ rDNA sequences, and would probably allow a number of socalled 'unculturable/uncultured' bacterial species to be assigned to existing lineages. The generation of sequence data from cultured organisms is therefore a prerequisite for a more realistic interpretation of microbial diversity. In order to build up an overview of microbial diversity from all studied environments, it is paramount that previously determined clone sequences are included in phylogenetic analyses of new cultured micro-organisms.

\section{DESCRIPTION OF NEW TAXA}

\section{Verrucomicrobiales Ward-Rainey, Rainey, Schlesner and Stackebrandt (ord. nov.)}

ver.ru'co.mi.cro.bi.a'les. Verrucomicrobiaceae type family of the order, -ales ending to denote an order, Verrucomicrobiales the Verrucomicrobiaceae order. The description is the same as for the type family.

\section{Verrucomicrobiaceae Ward-Rainey, Rainey, Schlesner and Stackebrandt (fam. nov.)}

ver.ru'co.mi.cro.bi.a'ce.ae. Verrucomicrobium type genus of the family, -eae ending to denote a family. Verrucomicrobiaceae the Verrucomicrobium family. The descrip- 
tion is based on that of the genus Verrucomicrobium (Schlesner, 1987).

Unicellular, Gram-negative bacteria with numerous fimbriate prosthecae extending in all directions from the cell surface. Isolated from aquatic environments and found as 16S rDNA clone sequences in soil. Phylogenetically, represents a phylum of the domain Bacteria. The presence of signature nucleotides in the $16 \mathrm{~S}$ rDNA sequences of the type species of the type genus of the family, and of uncultured representatives of the family from soil, define this family phylogenetically. DNA base composition $57 \cdot 9-59 \cdot 3 \mathrm{~mol} \% \mathrm{G}+\mathrm{C}$ (one species).

\section{REFERENCES}

Albrecht, W., Fischer, A., Smida, J. \& Stackebrandt, E. (1987). Verrucomicrobium spinosum, a eubacterium representing an ancient line of descent. Syst Appl Microbiol 10, 57-62.

Barns, S. M., Fundyga, R. E., Jeffries, M. W. \& Pace, N. R. (1994). Remarkable archaeal diversity detected in a Yellowstone National Park hot spring environment. Proc Natl Acad Sci USA 91, 1609-1613.

Britschgi, T. B. \& Giovannoni, S. J. (1991). Phylogenetic analysis of a natural marine bacterioplankton population by rRNA gene cloning and sequencing. Appl Environ Microbiol 57, 1707-1713.

Brosius, J., Palmer, M. L., Kennedy, J. P. \& Noller, H. P. (1978). Complete nucleotide sequence of a $16 \mathrm{~S}$ ribosomal RNA gene from Escherichia coli. Proc Natl Acad Sci US A 75, 4801-4805.

De Long, E. F. (1992). Archaea in coastal marine environments. Proc Natl Acad Sci US A 89, 5685-5689.

De Long, E. F., Wu, K. Y., Prézelin, B. B. \& Jovine, R. V. M. (1994). High abundance of Archaea in Antarctic marine picoplankton. Nature 371, 695-697.

De Soete, G. (1983). A least squares algorithm for fitting additive trees to proximity data. Psychometrika 48, 621-626.

Felsenstein, J. (1993). PHYLIP (phylogenetic inference package) version 3.5.1. Seattle: Department of Genetics, University of Washington.

Fuhrman, J. A., McCallum, K. \& Davis, A. A. (1993). Phylogenetic diversity of subsurface marine microbial communities from the Atlantic and Pacific Oceans. Appl Environ Microbiol 59, 1294-1302.

Fuhrman, J. A., Lee, S. H., Masuchi, Y., Davis, A. A. \& Wilcox, R. M. (1994). Characterization of marine prokaryotic communities via DNA and RNA. Microb Ecol 28, 133-145.
Giovannoni, S. J., Britschgi, T. B., Moyer, C. L. \& Field, K. G. (1990). Genetic diversity in Sargasso Sea bacterioplankton. Nature $345,60-63$.

Jukes, T. H. \& Cantor, C. R. (1969). Evolution of protein molecules. In Mammalian Protein Metabolism, pp. 21-132. Edited by H. N. Munro. New York: Academic Press.

Liesack, W. \& Stackebrandt, E. (1992a). Unculturable microbes detected by molecular sequences and probes. Biodivers Conserv 1 , 250-262.

Liesack, W. \& Stackebrandt, E. (1992b). Occurrence of novel groups of the domain Bacteria as revealed by analysis of genetic material isolated from an Australian terrestrial environment. $J$ Bacteriol 174, 5072-5078.

Rainey, F. A., Dorsch, M., Morgan, H. W. \& Stackebrandt, E. (1992). 16S rDNA analysis of Spirochaeta thermophila: its phylogenetic position and implications for the systematics of the order Spirocbaetales. Syst Appl Microbiol 15, 197-202.

Schlesner, H. (1986). Pirella marina sp. nov., a budding, peptidoglycan-less bacterium from brackish water. Syst Appl Microbiol 8, 177-180.

Schlesner, H. (1987). Verrucomicrobium spinosum gen. nov., sp. nov.: a fimbriated prosthecate bacterium. Syst Appl Microbiol 10, 54-56.

Schmidt, T. M., DeLong, E. F. \& Pace, N. R. (1991). Analysis of a marine picoplankton community by $16 \mathrm{~S}$ rRNA gene cloning and sequencing. $J$ Bacteriol 173, 4371-4378.

Stackebrandt, E., Liesack, W. \& Goebel, B. M. (1993). Bacterial diversity in a soil sample from a subtropical Australian environment as determined by $16 \mathrm{~S}$ rDNA analysis. F ASEB J 7, 232-236.

Ward, D. M., Weller, R. \& Bateson, M. M. (1990). 16S rRNA sequences reveal numerous uncultured inhabitants in a natural community. Nature 345, 63-65.

Ward, N., Rainey, F. A., Goebel, B. \& Stackebrandt, E. (1995). Identifying and culturing the 'unculturables' - a challenge for microbiologists. In Microbial Diversity and Ecosystem Function, pp. 89-110. Edited by D. Allsopp, D. L. Hawksworth \& R. R. Colwell. Wallingford: CAB International.

Weller, R., Weller, W. J. \& Ward, D. M. (1991). 16S rRNA sequences of uncultivated hot spring cyanobacteria mat inhabitants retrieved as randomly primed cDNA. Appl Environ Microbiol 57, $1146-1151$.

Received 6 February 1995; revised 3 July 1995; accepted 28 July 1995. 


\section{CORRIGENDUM}

\section{Cholera toxin (CTX) genetic element in Vibrio cholerae 0139}

Rupak K. Bhadra, Susanta Roychoudhury, Rajat K. Banerjee, Sujata Kar, Ruma Majumdar, Sanghamitra Sengupta, Soma Chatterjee, Gopal Khetawat and Jyotirmoy Das

Microbiology (1995), 141, 1977-1983

p. 1978, Table 1:

MO1 Clinical, Madras, India O139, $\mathrm{CT}^{+}$

should read
MO1
Clinical, Madras, India
O1, E1 Tor, $\mathrm{CT}^{+}$ 